\title{
Type12 and Type56: a load structure comparison in TRNSYS
}

\author{
Helena Persson ${ }^{1, *}$, Bengt Perers ${ }^{2}$, Bo Carlsson ${ }^{1}$ \\ ${ }^{1}$ School of Pure and Applied Natural Sciences, Linnaeus University, SE 39182 Kalmar, Sweden \\ ${ }^{2}$ Department of Civil Engineering DTU, DK-2800 Kgs. Lyngby, Denmark \\ * Corresponding author. Tel: +46 731424645, E-mail: helena.persson@Inu.se
}

\begin{abstract}
An investigation of the accuracy, advantages and disadvantages of using the simpler degree day house load-model Type 12 as a replacement for the more complex multi-zone Type 56 has been made. Results show that Type 12 provides sufficient accuracy for all systems including a storage tank capable of holding at least one day load. A discussion whether Type 12 is an accurate model for other situations is made.
\end{abstract}

Keywords: TRNSYS, Renewable energy, Solar Combi, Programming, Type, 56

\section{Introduction}

The modeling of solar combisystems in the academic community is often done in a commercially available fortran based simulation environment named TRNSYS [1]. These systems often contain some form of heating system (heat pumps, solar collectors) and some form of load that uses the energy created (building, hot water load). The load is often connected to some form of weather data, deciding the ambient conditions. The interaction between the heat sources and loads form a TRNSYS deck, a series of component models connected to each other to provide information about a system. Here we seek to investigate the impact of the house load model that is chosen. The load structures that will be investigated are the two most common types of buildings used in TRNSYS: the very simple single-zone degree day model with internal gains described by Type 12, and the much more complex multi-zone model Type 56.

Previous work includes Olof Hallström [2], who in his thesis compared Type 12 to a much more complex model developed at Lund University. He found that even though Type 12 was surprisingly accurate for most conditions, especially during low indoor house temperatures, the drawbacks of the type made the choice between Type 12 and Type 56 hard to determine. He identified these drawbacks as the constant heat loss coefficient and the difficulty to include stored solar radiation. It can be noted however, that Type 56 also has a constant heat loss coefficient. Previous simplifications of TRNSYS models have among many others been performed by T. P. McDowell [3], completing a ground source model and by P. T. TSILINGIRIS [4] and his solar heating designs. In both cases a drastically decreased calculation time at low accuracy cost was reached.

Simplifying a deck has the advantage of a decreased calculation time, which can be a major problem in decks taking many hours or even days to complete, especially if a large amount of runs are desired for statistical or optimization purposes. A simpler deck is also highly advantageous for applications directed at the industry, installers and education, such as Climate Well [5] or Winsun Villa [6]. Winsun Villa contains a slightly modified version of Type 12. The conclusions of this publication will be used for the Flexi-Fuel project [7], which has strong connections to the industry and its installers and customers. The objective of the following paper is to determine the accuracy, calculation time and complexity of Type 56 and Type 12 under different conditions. 


\section{Methodology}

\subsection{TRNSYS}

TRNSYS is a system simulation computational tool developed by Wisconsin University that allows for dynamic simulation of systems using variable time steps. It allows for systems, particularly heating systems, to be created by connecting several components, known as types. These types are mathematical subroutines, i.e. programs, which describe for example a pipe, a house or a heat pump. Apart from the possibility of self-made types, TRNSYS contains a large number of readymade types, and a large number of types are also developed by different institutes and available commercially or for free.

\subsubsection{Available load-describing Types}

There are several commercially available load models available, but we limit ourselves to observing those Types that are included in the basic TRNSYS package. These are: Type 12, the simplest model, Type 88, a version of Type 12 that also includes some internal gains, (It may be noted that these internal gains are being modeled directly in Type 12 under "misc heat gain”, for the investigations performed in this paper.) Type 56 which is a very complex and thorough multi-zone building model, and finally Type 19 a single zone building that is less complex then Type 56, but still requires the input of a large number of parameters. We choose to observe Type 12 and 56 since they are the source of the other models and represent the extremes in simplicity/speed and complexity/accuracy.

\subsubsection{TYPE 56}

Type 56 describes a building with multiple thermal zones, i.e. rooms. The model uses data from wall and window materials and thicknesses. Each room has a homogenous temperature, and radiation heat between the rooms is based on the room area. Heat addition from solar direct and diffuse radiation is calculated for each room depending on window and heat transfer properties.

\subsubsection{TYPE 12}

Type 12 is a simple degree-day, single-zone, single capacitance building model with internal gains. The model uses an effective heat capacity for the entire building together with the difference between indoor and outdoor climate to create a heating need. The load is corrected for internal gains. The use of a single heat capacity does not provide any information on solar radiation, which can have significant impact during summer. In this work the solar radiation is added to the internal gain, time step by time step. Duffie and Beckman reasons that since heat capacity effects are difficult to model with a single node when the outdoor temperature is fluctuating around the indoor temperature, Type 12 becomes less reliable for cooling loads. [8]. This has not been investigated here.

\subsection{The House}

As a reference building the IEA Task 32 building which is based on the IEA Task 26 reference building was used. [9] The reason for this choice is simply that it is a well defined and known building suitable for comparison purposes. Two levels of insulation are chosen to simulate an energy need of 60 or $100 \mathrm{kWh} / \mathrm{m}^{2} \mathrm{a}$. The building consists of a two storey house with the specifications described in Table 1,2 and 3. 
Table 1. Building Properties.

\begin{tabular}{|c|c|c|c|c|c|c|c|c|}
\hline & & $\begin{array}{c}\text { SFH60 } \\
{[\mathrm{m}]}\end{array}$ & $\begin{array}{c}\text { SFH100 } \\
{[\mathrm{m}]} \\
\end{array}$ & {$\left[\mathrm{kg} / \mathrm{m}^{3}\right]$} & [W/mK] & [kJ/kgK] & $\begin{array}{c}\text { SFH60 } \\
{\left[\mathrm{W} / \mathbf{m}^{2} \mathbf{K}\right]}\end{array}$ & $\begin{array}{r}\mathrm{SFH100} \\
{\left[\mathrm{W} / \mathbf{m}^{2} \mathbf{K}\right]} \\
\end{array}$ \\
\hline \multirow[t]{5}{*}{ external wall } & plaster inside & 0.015 & -- & 1200 & 0.600 & 1.00 & & \\
\hline & Viertl brick & 0.210 & -- & 1380 & 0.700 & 1.00 & 0.154 & 0.491 \\
\hline & EPS & 0.120 & 0.060 & 17 & 0.040 & 0.70 & & \\
\hline & plaster outside & 0.003 & -- & 1800 & 0.700 & 1.00 & & \\
\hline & $\Sigma$ & 0.468 & 0.288 & & & & & \\
\hline \multirow[t]{5}{*}{ ground floor } & Wood & 0.015 & -- & 600 & 0.150 & 2.50 & & \\
\hline & plaster floor & 0.060 & -- & 2000 & 1.400 & 1.00 & 0.157 & 0.561 \\
\hline & XPS & 0.120 & 0.060 & 38 & 0.037 & 1.45 & & \\
\hline & Concrete & 0.150 & -- & 2000 & 1.330 & 1.08 & & \\
\hline & $\Sigma$ & 0.445 & 0.285 & & & & & \\
\hline \multirow[t]{5}{*}{ roof ceiling } & Gypsumboard & 0.025 & -- & 900 & 0.211 & 1.00 & & \\
\hline & Plywood & 0.015 & -- & 300 & 0.081 & 2.50 & 0.119 & 0.380 \\
\hline & Rockwool & 0.200 & 0.060 & 60 & 0.036 & 1.03 & & \\
\hline & Plywood & 0.015 & -- & 300 & 0.081 & 2.50 & & \\
\hline & $\Sigma$ & 0.335 & 0.115 & & & & & \\
\hline internal wall & Clinker & 0.200 & -- & 650 & 0.230 & 0.92 & 0.962 & 0.962 \\
\hline
\end{tabular}

Table 2. Window Area.

\begin{tabular}{cccc}
\hline & $\begin{array}{c}\text { window } \\
\text { area } \\
{\left[\mathbf{m}^{2}\right]}\end{array}$ & $\begin{array}{c}\text { window } \\
\text { quotient } \\
{[\%]}\end{array}$ & $\begin{array}{c}\text { total } \\
\text { area } \\
{\left[\mathbf{m}^{2}\right]}\end{array}$ \\
\hline \hline South & 12.0 & 24.0 & 50.0 \\
East & 4.0 & 9.9 & 40.5 \\
West & 4.0 & 9.9 & 40.5 \\
North & 3.0 & 6.0 & 50.0 \\
Summary & 23.0 & 12.7 & 181.0 \\
\hline
\end{tabular}

Table 3. Window Properties

\begin{tabular}{|c|c|c|c|c|c|}
\hline building & $\begin{array}{c}\text { UWINDOW } \\
{\left[\mathrm{W} / \mathbf{m}^{2} \mathrm{~K}\right]}\end{array}$ & $\begin{array}{c}\text { g-Value } \\
{[-]}\end{array}$ & $\begin{array}{l}\text { UFRAME } \\
\text { [W/m² }\end{array}$ & $\begin{array}{c}\text { construction } \\
{[\mathrm{mm}]}\end{array}$ & WindowID \\
\hline $\begin{array}{l}\text { SFH60 } \\
\end{array}$ & 1.4 & 0.622 & 2.3 & $4 / 16 / 3$ & 2004 \\
\hline SFH100 & 2.83 & 0.755 & 2.3 & $4 / 16 / 4$ & 1202 \\
\hline
\end{tabular}

A more detailed description on the house's architectural design, internal load and ventilation can be found in [9].

\subsubsection{Estimating UA-values}

Type 12 uses a single overall UA heat transfer value for the entire house. This value can be estimated by summarizing the U-values from all walls and windows in the building. An effective UA value for the ventilation can be added as this has the same temperature difference as the transmission losses. 


$$
\begin{aligned}
& \text { UA }=U_{\text {WALL1 }} * A_{\text {WALL1 } 1}+U_{\text {WALL2 }} * A_{\text {WALL2 }}+U_{\text {WALL3 }} * A_{\text {WALL } 3}+U_{\text {WALL } 4} * A_{\text {WALL } 4}+U_{\text {WINDOWS }} * A_{\text {Windows }}+ \\
& +U_{\text {Roof }} * A_{\text {Roof }}+U_{\text {Floor }} * A_{\text {Floor }}+V_{\text {house }} * n * \frac{1}{3600} *\left(1-\eta_{\text {h }}\right) * \rho_{\text {air }} * C_{p_{-} \text {air }}
\end{aligned}
$$

\subsubsection{Estimating solar radiation gain}

In Type 12, Solar gains through windows can be estimated by adding the window area for each direction and multiply it with a transmission value (In this publication 0.6 has been used for all cases) as described in (2)

$$
S=\operatorname{trm}\left(W A_{N}+W A_{E}+W A_{W}+W A_{S}\right)
$$

Where

trm $=$ transmission constant

$W A=$ Window area in the specified direction

This solar radiation gain value is then inserted into Type 12 through internal gains.

\subsubsection{Effective thermal capacitance of the house}

An effective thermal capacitance of the type 12 house can be estimated by adding up the thermal capacity for the individual parts of the house. Duffie and Beckman [8] give approximate values of $0.153 \mathrm{MJ} / \mathrm{m} 2 / \mathrm{K}$ for a medium house and $0.415 \mathrm{MJ} / \mathrm{m} 2 / \mathrm{K}$ for a heavy house and up to 0.810 for a very heavy building. This corresponds in this case (with $140 \mathrm{~m} 2$ total floor area) to $21 \mathrm{MJ} / \mathrm{K}, 58 \mathrm{MJ} / \mathrm{K}$ and $113 \mathrm{MJ} / \mathrm{K}$.

\section{Measurements}

Type 12 is deemed to be the less accurate model, and so when Type 56 and Type 12 are compared, any deviation from each other is considered to be due to an inaccuracy of Type 12 .

\subsection{The Timescale}

Fig 1 shows the output of Type 12 and Type 56, as well as the difference between them. At first glance, the heating load required by Type 12 appears to be very inaccurate for both the well and the less insulated building as we see in the upper part of Fig.1. The whole line depicting the difference between the two types is in the order of $50 \%$ for most of the year. 

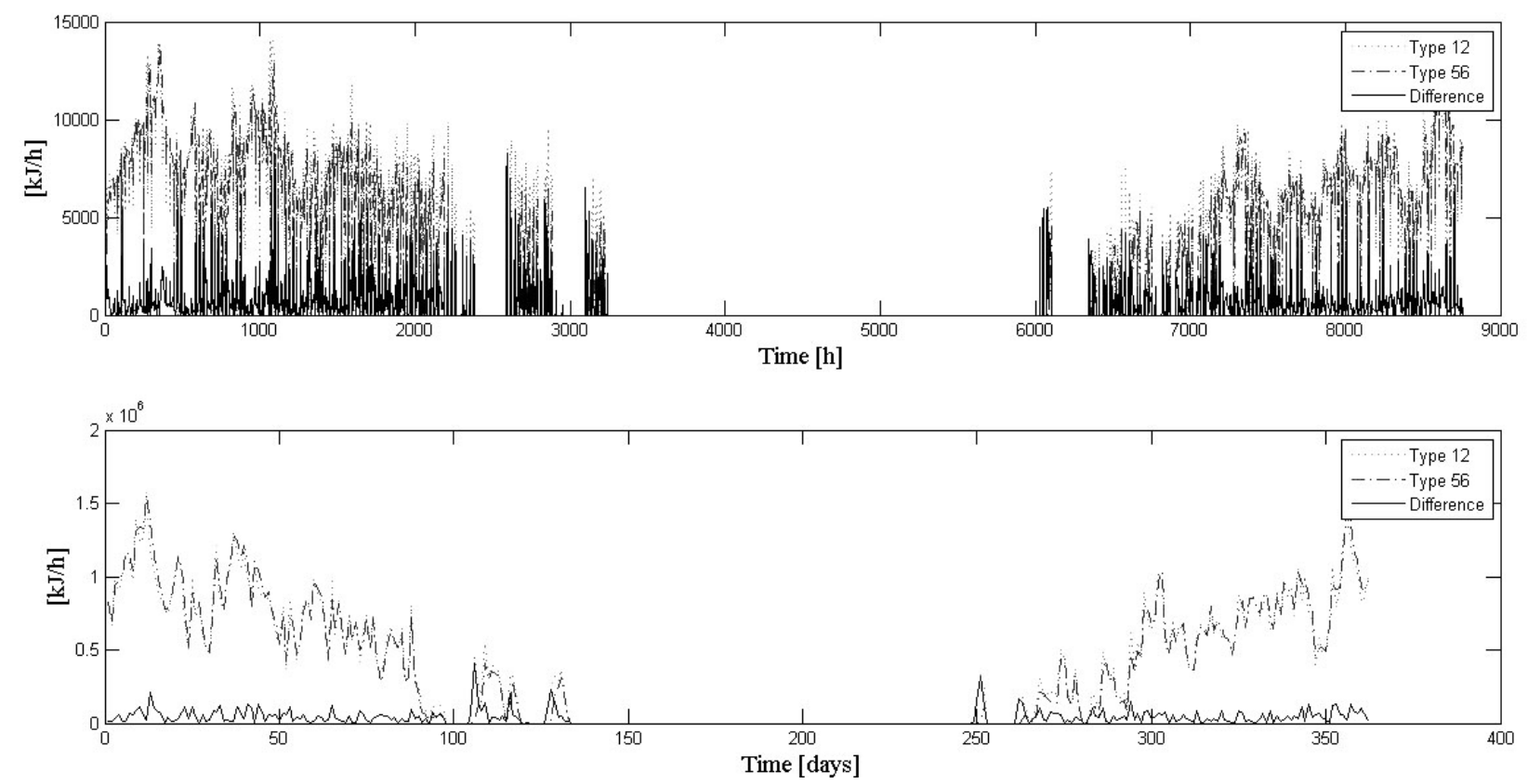

Fig.1 The output from Type12 and 56 with 12min time step (upper diagram) and $12 \mathrm{~h}$ time step (lower diagram)

Possible heat pumps or solar collectors connected to a system are highly dependent on the temperature of the incoming flow. To gain sufficient accuracy for such heat sources a time step of a few minutes is required. The flow to such sources is often connected to some form of storage, such as a tank, between the load and the heat source. If for example a storage tank has the capacity of storing the energy required for heating a house for one day, a heat demand for one day is sufficient. When we integrate the output of both Type 56 and Type 12 over one day, we see a definite increase in agreement between the models as shown in the lower part of Fig.1.

\subsection{The Accuracy of Type 12}

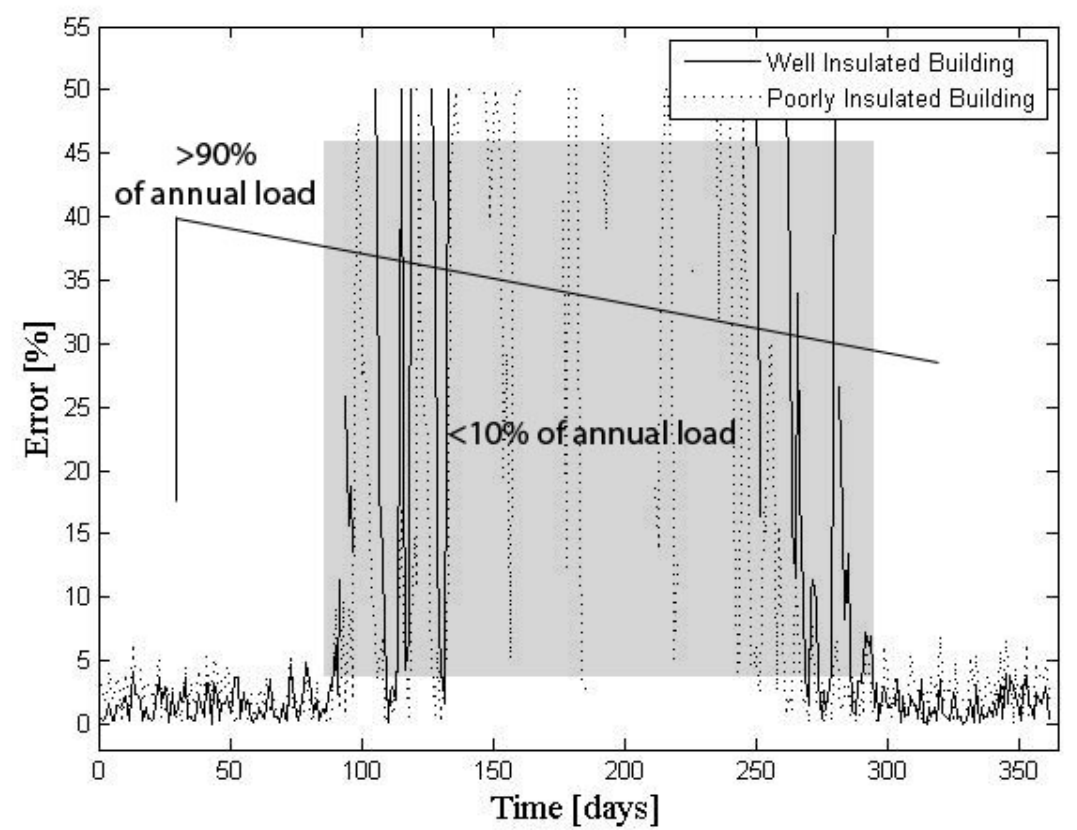

Fig. 2. The Difference in output for Type 12 and 56 for a poorly and a well insulated building 
Fig. 2 shows the error in percentage over one year. For the colder periods of the year the percentual error keeps below $7 \%$ for both levels of insulation. $7 \%$ is most likely a smaller error then those arising from building uncertainties such as cracs in the building shell or moisture in the isolation. Even though the error grows large in summertime, less than ten percent of the annual energy requirement occurs during this period. This means that for over $90 \%$ of the annual load, Type 12 performs acceptably. The yearly error becomes approximately $8 \%$.

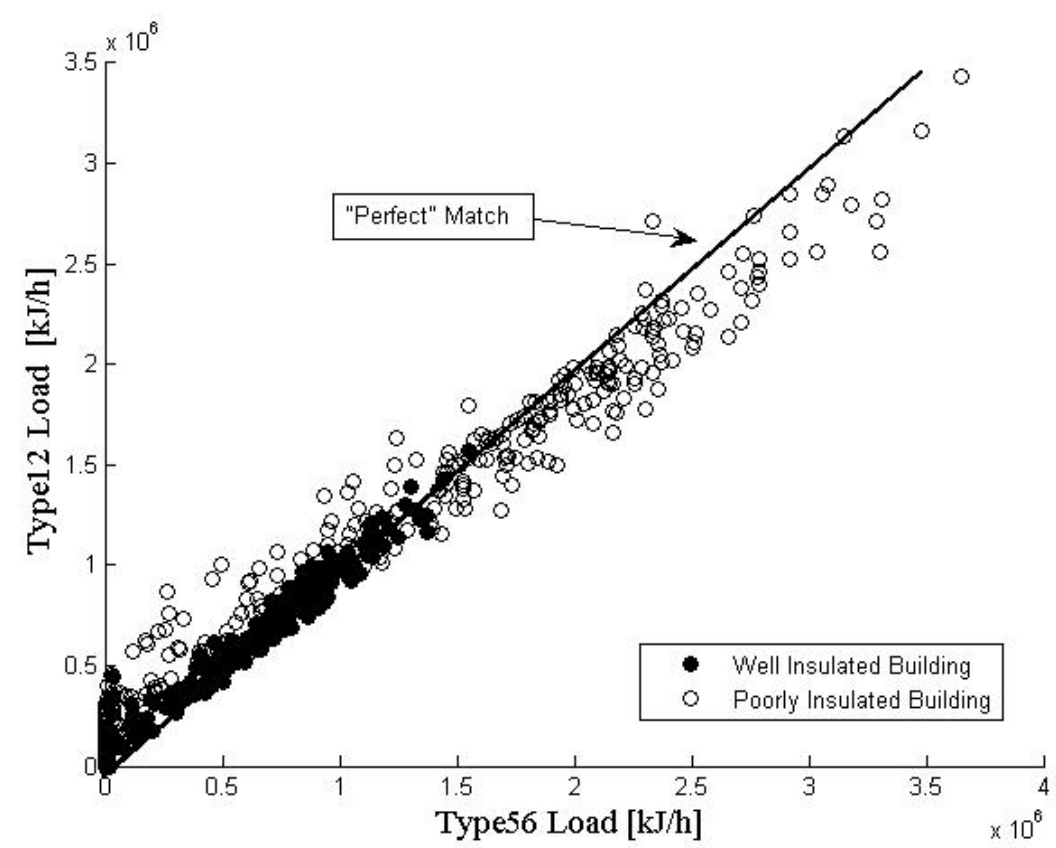

Fig. 2. Type 12 vs. Type 56 for a poorly and a well isolated building

Fig. 3 shows the output from the models plotted against each other. The error in output seems to be evenly distributed at the base of the line. The filled circles showing the well insulated building are closer to the line indicating that the overall UA value was a good guess for this case. At higher values we see a drift downwards, indicating that Type 12 underestimates the energy requirement for cold days, and overestimates it for warm days. This may be due to the fact that Type 12 does not store solar heat in the interior of the building.

\subsection{The Phasing of Type 56}

The difference in how the models react to outdoor temperatures is described in Fig. 4 and Fig. 5. Fig. 4 shows a zoomed in view of 3 days with the light gray line as outdoor temperature, the highly oscillating line as Type 12 and the less oscillating as Type 56. In this simulation, all windows, internal load and ventilation has been removed to get the crudest model possible. As seen in the image, Type 56 has a slight delay compared to the outdoor temperature, as might be expected by a more complex building model. 


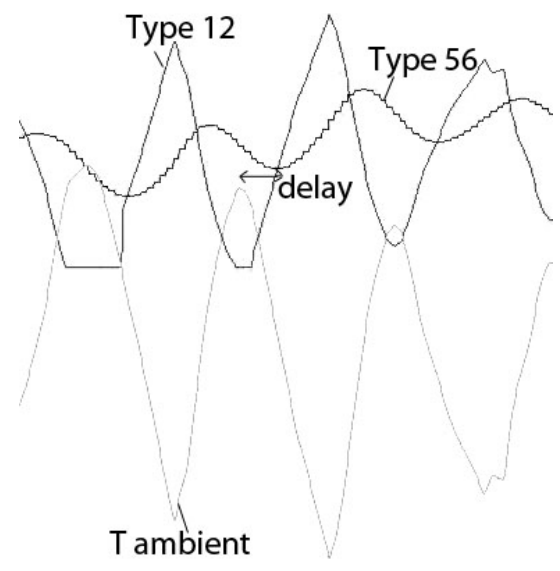

Fig. 4. The Delay of Type 56 when no windows are present

Fig. 5 shows two days but this time windows have been added to both models. Radiation coming through windows provides an instantaneous addition of heat, resulting in a model that responds much faster to outdoor weather. It could be argued that adding radiation through windows and ventilation provides a Type 56 that behaves more like Type 12 .

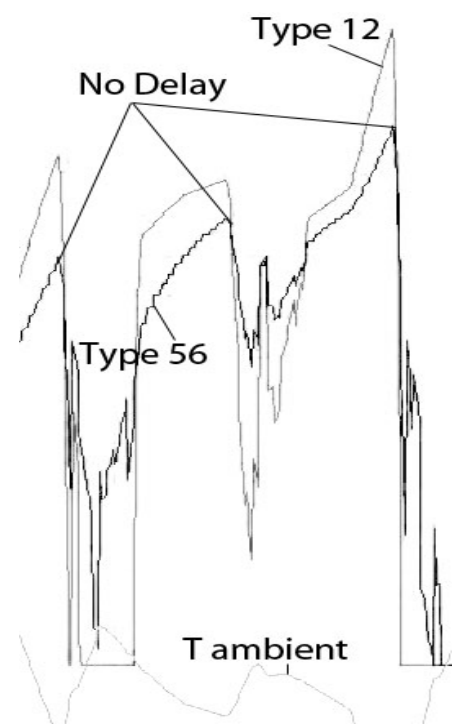

Fig. 5. No Delay of Type 56 when windows are present

\subsection{Calculation Speed}

Type 12 takes approximately half the simulation time for one year compared to Type 56 (23s against 42s). The time step was then rather long, 12 minutes. In a full deck the tank may call the load several times before it converges, 10 times or more is not unusual. Also if a very short time step is used, this difference in calculation speed can have a significant impact on the usability of the deck.

\section{Discussion}

Considering the results presented above, Type 12 seems to be a good approximation under the right circumstances. It can be recommended for systems including a tank or other form of storage, or for systems that do not require high temporal resolution. The usage of Type 12 can not be recommended in applications consisting of heat sources without any storage. Type 12 
only requires one UA parameter, which can be estimated as described above. In practical applications, the complete drawings of a building may not be easily accessible, or as in the case of the Flexi-Fuel project [7], it may prove very disadvantageous for a salesman to ask the client for every constructive layer in the wall before being able to demonstrate his/her products. In a real building the heat load will also be influenced by the wind dependent infiltration rate and quality of insulation work, as well as user behavior concerning choice of room temperature and for example open windows in some rooms periods of the day or night. The simulation model in the flexifuel project is aiming at fast but realistic system simulations and then type 12 may be the best choice.

\section{References}

[1] Klein et al., 2000, http://sel.me.wisc.edu/trnsys/

[2] O. Hallstrom, Solar Cooling Dimensioning, Modelling of Solar Cooling Installations Using a Thermal Chemical Accumulator from Climate Well AB, Thesis, 2008

[3] T. P. McDowell, J. W. Thornton, and M. J. Duffy, Comparison of a Ground-Coupling Reference standard model to simplified approaches, Eleventh International IBPSA Conference Glasgow, Scotland July 27-30, 2009

[4] P. T. Tsilingiris, Solar Water Design - A new simplified dynamic approach, Solar Energy Vol. 57, No. 1, pp. 19-28, 1996

[5] ClimateWell AB. www.climatewell.com 20070121.

[6] Winsun Villa, www.ebd.lth.se

[7] H. Persson, B. Carlsson, B. Perers, P Olsson and Å. Hjort, Test Plant and Development of Tools for Design of Combi-Heating Systems for large building, Eurosun2010

[8] Duffie, J. Beckman, W., Solar Engineering of Thermal Processes, John Wiley \& Sons, Inc. 2006.

[9] R. Heimrath, M. Haller, A Report of IEA SHC - Task 32, 2007 